\title{
Lesbian Shared Biological Motherhood: The Ethics of IVF with Reception of Oocytes from Partner
}

Kristin Zeiler and Anna Malmquist

\section{Linköping University Post Print}

\section{Tweet}

N.B.: When citing this work, cite the original article.

The original publication is available at www.springerlink.com:

Kristin Zeiler and Anna Malmquist, Lesbian Shared Biological Motherhood: The Ethics of IVF with Reception of Oocytes from Partner, 2014, Medicine, Health care and Philosophy, Jan. 2014.

http://dx.doi.org/10.1007/s11019-013-9538-5

Copyright: Springer Verlag (Germany) http://www.springerlink.com/?MUD=MP

Postprint available at: Linköping University Electronic Press http://urn.kb.se/resolve?urn=urn:nbn:se:liu:diva-103825 


\title{
Lesbian Shared Biological Motherhood:
}

\section{The Ethics of IVF with Reception of Oocytes from Partner}

Published as early view on-line publication in Medicine, Health Care and Philosophy, 2013

Kristin Zeiler $^{1}$ and Anna Malmquist ${ }^{2}$

1. The Swedish Collegium for Advanced Study, Uppsala University, and the Department of Medical and Health Sciences, Linköping University.

2. Division of Psychology, Department of Behavioural Sciences and Learning, Linköping University.

\begin{abstract}
IVF with ROPA (Reception of Oocytes from Partners) allows lesbian mothers to share biological motherhood. The gestational mother receives an egg from her partner who becomes the genetic mother. This article examines the ethics of IVF with ROPA with a focus on the welfare of the woman and the resulting child, on whether ROPA qualifies as a "legitimate" medical therapy that falls within the goals of medicine, and on the meaning and value attributed to a biologically shared bond between parents and child. We also contrast IVF with ROPA with egg donor IVF for heterosexual couples and intrafamilial live uterus transplantation with IVF, and show how Swedish legislation makes certain ways of sharing biological bonds out of place. In Sweden, IVF with ROPA is illegal, egg donor IVF for heterosexual couples is allowed and practiced as is sperm donor IVF for lesbians, and live uterus transplantation is performed within a research project (though not allowed in regular health care). But is ROPA really ethically more problematic than these other cases? The article argues that IVF with ROPA gives rise to fewer ethical questions than does live uterus transplantation with IVF and, in some cases, egg donor IVF.
\end{abstract}

\section{Keywords}

Ethics, ROPA, oocyte donation, embryo donation, shared biological motherhood, lesbian, live uterus transplantation, egg donor IVF. 


\section{Lesbian Shared Biological Motherhood:}

\section{The Ethics of IVF with Reception of Oocytes from Partner}

\section{Introduction}

For couples with fertility problems and a longing to parent, adoption and foster care are possible alternatives. Furthermore, assisted reproduction offers a plethora of additional routes. All of these routes to parenthood require ethical considerations.

If a woman in a heterosexual couple has no eggs or insufficient quality of her eggs but her male partner is fertile, the couple may ask for in vitro fertilization (hereafter referred to as IVF) with egg donation. In such a procedure, the couple will receive an egg from a donor. If treatment is successful, the male partner will become the genetic father of the child and the female partner the gestational but not the genetic mother.

If a woman in a heterosexual couple instead has eggs but no or a non-functional uterus, there has until recently been one route for her to achieve genetic motherhood: gestational surrogacy, where a surrogate mother agrees to have the commissioning couple’s embryo implanted into her own uterus. Besides this, another option may soon be available. The first live uterus transplantation took place in Saudi Arabia, in 2000, but the uterus had to be removed after three months (Fageeh et al. 2002). More recently, in Sweden in autumn 2012, Mats Brännström and colleagues performed the world's first mother-to-daughter live uterus transplantation (Hansen 2012). Live uterus transplantation may be performed to give a woman who has eggs but no functional uterus the possibility of becoming the gestational and genetic mother, via IVF.

These cases of assisted reproduction technologies bring to light different conceptions of parenthood: genetic parenthood, where parenthood is understood as arising from genetic derivation, gestational parenthood, where parenthood arises from pregnancy and childbirth, and intentional parenthood, where parenthood arises from the intention to bring into existence and/or rear the child. The term biological parenthood commonly refers to genetic and/or gestational parenthood and we will follow this usage. 
Egg donor IVF, gestational surrogacy and live uterus transplantation with IVF are all technologies that could provide options not least for heterosexual couples, when the female partner has impaired fertility. If a woman with fertility problems instead lives in a lesbian relationship, and if the couple wants to have a child, the most obvious route to parenthood is that the infertile woman's partner, if she is fertile, undergoes sperm donor insemination. In this case, one partner will be the genetic and gestational mother, while the other woman will have no biological bond to the child. Recently, however, one more alternative has become possible for lesbian women.

In IVF with Reception of Oocytes from Partner (hereafter referred to as ROPA), one of the women in the lesbian couple is the gestational mother who receives an egg from the other woman, the genetic mother, after the egg has been fertilized by donor sperm. ${ }^{1}$ This allows lesbian women to share biological motherhood. It allows a lesbian woman who has eggs but no functional uterus to become the genetic mother of a child carried by her partner; it allows a lesbian woman who has a functional uterus but no eggs or insufficient quality of eggs to experience pregnancy and become a gestational mother to a child who is genetically linked to her partner. It also allows reproductively healthy lesbian women to share biological motherhood. ${ }^{2}$

${ }^{1}$ Reception of Oocytes from Partner is the term used by Marina and colleagues (2010). We use their terminology because this is accepted practice, at least in the Spanish clinical context. However, another way of framing this treatment is as biological co-mothering or egg sharing. In contrast to the notion of egg sharing used in the UK (where the term denotes the practice of offering IVF at a subsidized cost to women who donate eggs to research), egg sharing in this context implies sharing eggs with one’s partner. Furthermore, some see ROPA as a form of embryo donation, which currently is available at some IVF clinics in for instance the UK, the US, Canada and Russia (Statens medicinetiska råd [The Swedish National Council on Medical Ethics] 2013:1).

${ }^{2}$ ROPA could also offer a possibility for a transsexual man who has undergone female to male treatment and surgery and who has kept his oocytes. If such a man has a female partner she may 
Few ethical analyses of ROPA have been conducted to date. In an article presenting their initial experiences of the procedure, Spanish IVF doctor Marina and colleagues suggest that ROPA promotes lesbian women's autonomy in the area of reproduction (since it is performed at the explicit request of such women and after they have been informed about the procedure), is a means to do good for the women who long to have a child together and for the particular child who is brought into existence (since they presume that existence is better than non-existence), and implies no harm (since studies indicate that the child's development will not be hampered by living with two mothers) (Marina et al. 2010). Others, however, suggest that this is to omit issues such as whether offering IVF with ROPA really can qualify as "good" clinical practice in cases where the couple could have conceived through donor insemination, and how to understand the meaning for human couples of having a child that is biologically related to both partners (Dondrop 2010; Chan et al. 1993).

This article examines ethical aspects of IVF with ROPA. First, it outlines different reasons for couples to ask for IVF with ROPA and presents a case of Swedish lesbian women for whom IVF with ROPA would have been the optimal choice, had it been allowed in Sweden. Second, it situates IVF with ROPA within the larger context of assisted reproduction and examines the ethics of IVF with ROPA with a focus on the welfare of the women and the resulting child including IVF-related risks for the women and the child, on whether ROPA qualifies as a "legitimate" medical therapy that falls within the goals of medicine, and on the meaning and value attributed to a biologically shared bond between parents. Third, it contrasts IVF with ROPA with egg donor IVF for a heterosexual couple and with live uterus transplantation with IVF. Fourth, it discusses IVF with ROPA in relation to Swedish legislation and ethical discussion in the Swedish National Board of Medical Ethics. ROPA is currently prohibited by Swedish law, while egg donor IVF for heterosexual couples is allowed and practiced as is sperm donor IVF for lesbians, and live uterus transplantation with IVF is performed in the context

carry their child, and the embryo may be the result of one of his oocytes being fertilized with donor sperm. 
of a research project though not allowed in regular health care. We discuss how Swedish legislation forms an ethically interesting case that renders certain forms of sharing biological bonds out of place, and argue that IVF with ROPA evokes fewer ethical problems than live uterus transplantation with IVF and some cases of egg donor IVF.

Our reasoning starts from the accepted legal position in Western countries such as Sweden and the UK, and several states in the US, where lesbian women are allowed to use assisted reproduction treatment to have a child. We will not discuss whether lesbian women should be allowed to use assisted reproduction in order to have a child at all. 


\section{Making sense of lesbians' wish for ROPA}

Consider first the case of Martina and Agnes. ${ }^{3}$ When Martina and Agnes met, Martina was in her midthirties and Agnes in her late twenties. Like most other Swedish lesbian couples, both women desired to be gestational mothers (Malmquist submitted). The couple decided to inseminate the older spouse first and the younger later. Martina was inseminated with donor semen at a fertility clinic and became pregnant on the second attempt. She experienced an uncomplicated pregnancy and delivery, and gave birth to the couple's first child, Lova. Shortly after, Agnes started the process of getting pregnant, but met with difficulties. After a series of inseminations and IVF-attempts, Agnes had experienced several miscarriages, one of them being severe enough for her to undergo surgery and lose one of her ovaries. When she at last went through a full length pregnancy, she suffered from serious medical complications and was hospitalized during the time she carried the child. She described the delivery as extremely complicated, requiring acute surgery.

After the birth of their second child Ebba, the couple discussed the possibilities of having a third child. Martina had passed her fortieth birthday and, like most women of her age, she expected her egg quality to have rapidly declined. Agnes said that she had had "a hard time becoming pregnant, a hard time being pregnant, and a hard time giving birth,” hence it was not realistic for her to go through another pregnancy. However, the couple still had frozen embryos left after Agnes's pregnancy, i.e. eggs from Agnes fertilized with donor semen. In order for this couple to have a third child, ROPA would have been a solution, if the practice had been allowed. Martina, with declining egg quality but previous experience of an uncomplicated pregnancy and delivery could be the gestational mother to a child created with the already frozen fertilized eggs of Agnes.

\footnotetext{
${ }^{3}$ The parental couple was interviewed by Malmquist for a research project on lesbian parenting. Their
} names have been replaced by pseudonyms. Other publications from this project are Malmquist submitted; Malmquist, Möllerstrand, Wikström \& Zetterqvist Nelson 2013; Malmquist \& Zetterqvist Nelson 2013; Rozental \& Malmquist, accepted. 
Lesbian couples may ask for ROPA when one of the partners has no eggs or a low egg quality or when one of the partners has no or a dysfunctional uterus or has had a previous complicated pregnancy. We label these medical reasons for seeking ROPA. Couples may also ask for ROPA in order to implant their already frozen embryos, i.e. for embryo-related reasons. This is the case when a couple already has embryos left from one partner's previous pregnancy, wants to have them implanted, but prefers to switch birth mother for the next pregnancy. Depending on one’s conception of the embryo, one may also have ethical reasons for wanting to implant frozen embryos. Other lesbian women have a desire to become genetic mothers but have no desire for pregnancy (Pelka 2009). If the partner is willing to give birth, ROPA can be an attractive choice. Still others see ROPA as a primary choice in order to create a shared biological bond between both mothers and the same child. Of course, a combination of two or more motives can ground the desire for ROPA. In the case of Martina and Agnes their motivations for ROPA would have been both medical and related to their already frozen embryos.

\section{Ethical aspects of IVF with ROPA}

Just like other forms of IVF treatments, IVF with ROPA should only take place when the individuals involved in the treatment have had time and information enough to consider different alternatives. This is crucial in order to make possible informed and thought-through choices in assisted reproduction. Empirical research is informative in indicating the complexity of such choices, as when showing how women can experience IVF as a traumatic and in other ways emotionally turbulent means to achieve pregnancy (IVF "just takes over") and yet affirm their determination to achieve this end (Franklin 1997:115, 114; see also Baker 2004; Kirkman and Rosenthal 1999; Lundin 1997).

The issues of informed and thought-through choices and IVF patients' experiences of undergoing treatment tie neatly together with the importance of being given accurate and sufficiently detailed information as to IVF-related risks. 


\section{IVF-related risks}

When Marina and colleagues (2010) describe their practice of ROPA, they state that IVF treatment always implies a risk and that this is generally accepted. While this is accurate, it is also important to acknowledge the large bulk of research showing not only that IVF treatment can be experienced as emotionally turbulent and painful, but also that it is difficult to know beforehand how one will experience the repeated hormonal injections and the egg retrieval involving surgery (see Steuber and Solomon 2008; Redshaw et al. 2007; Delvigne and Rozenberg 2002; Baker 2004; Franklin 1997). In a review covering the past 25 years' research on emotional aspects of undergoing IVF, C. M. Verhaak and colleagues (2007) conclude that IVF is a multidimensional stressor that in many cases evokes anxiety, resulting mainly but not solely from the unpredictable outcome. (On the positive side, negative emotions tend to disappear when or if IVF results in childbirth.) Furthermore, there is a small but persisting risk - in the sense of risk as probability - of ovarian hyperstimulation syndrome with a potential fatal outcome (Delvigne and Rozenberg 2002). This can occur if the ovaries react strongly to the hormonal treatment, become enlarged and full of fluid-filled follicles that in turn can result in thrombosis or even death.

As pointed out by risk researchers, "the existence of particular uncertainties in outcomes are processed and transformed into a subjective perception that then guides behavior" (Slovik and Weber 2002:5). In this light, the general acceptance of the risks of IVF treatment needs to be understood against the larger cultural backdrop in many Western countries, where IVF treatments are becoming normalized both in the sense of becoming common and in the sense of being accepted as routes to having a child.

When evaluating the IVF-related risks of ROPA, we distinguish IVF with ROPA for lesbians with impaired fertility from IVF with ROPA for reproductively healthy women. Consider first the case in which both women have impaired fertility, i.e. when undergoing IVF treatment is their only path to parenthood (besides adoption or foster care, if these options are possible). IVF with ROPA in this case means that the women will share the risks related to egg retrieval, pregnancy and childbirth. For the woman providing eggs, the risks are related to the hormonal stimulation, including the risk of ovarian 
hyperstimulation, and complications during or after egg retrieval. For the woman receiving the embryo, the risks are related to pregnancy and delivery, with a somewhat higher risk of bleedings and miscarriage as compared to women pregnant with their own oocytes (Söderström-Anttila 2001).

Now, if only one of the women has impaired fertility, but her partner is reproductively healthy, this person could conceive through donor insemination and the couple could have a child together without undergoing IVF. If there are two equally effective and established alternative treatments that will result in the same desired goal, it is often ethically preferable to choose the treatment that involves less risk to the persons undergoing it. Such reasoning may be based on the principle of nonmaleficence. Having the healthy partner become pregnant through donor insemination, which involves less risk to the woman undergoing treatment, may then seem ethically preferable to IVF with ROPA.

However, as noted by gynecologist Janis H. Fox, IVF treatment is regularly offered to reproductively healthy heterosexual women when their male partners have low but existing sperm production. If such a couple longs for a child with whom they will have a shared genetic bond, they may seek medical assistance in the form of intracytoplasmic sperm injection, i.e. a version of IVF in which one single sperm is injected into an egg. Just like IVF with ROPA for reproductory healthy women, this route to parenthood implies medical risks for a reproductively healthy woman, who could just as well have become pregnant through sperm donor insemination. Fox (Chan 1993:213) remarks that "few physicians struggle over offering such couples the chance of creating a child together" and asks why lesbian women should not be offered the same possibility, if they wish it.

This makes clear the inconsistency in reasoning when it is seen as acceptable to offer IVF treatment to reproductory healthy heterosexual but not reproductory healthy lesbian women. Arguably, the above mentioned IVF-related risks for women should either be considered an ethical reason for refraining from IVF treatment for all reproductively healthy women, or not be considered as such, if one has accepted IVF for lesbians at all.

Furthermore, the reasoning above highlights that if the partner with impaired fertility longs for a biological bond to the child, IVF with ROPA and insemination are not two alternative treatments aimed at the same goal just as this is not the case with intracytoplasmic sperm injection and 
insemination with sperm donation for heterosexual couples. This is also applicable to cases where both women in the lesbian couple are reproductively healthy: IVF with ROPA involves higher medical risks for the partners than insemination, but if the couple desire a shared biological bond to the child, the results of the two paths to parenthood are not equivalent.

Finally, IVF-related risks for the child born after this procedure need to be considered as part of considerations regarding the welfare of the child. Some differences have been detected between children born after IVF and other children: a higher number of early births, lower weight at birth and a somewhat higher percentage of neural tube defects and esophagus atresia, the latter two conditions being operable after birth. However, these differences have been understood as not related to the IVF treatment as such but to a higher number of multiple births if more than one embryo is implanted into the woman's uterus, and the age and infertility of the parents (European Society of Human Reproduction and Embryology 2009). In relation to these risks, it is the medical status of the individuals that is of relevance.

\section{ROPA and "good" medical practice}

The consistency criterion also makes it problematic to question IVF with ROPA only and not to question other forms of IVF treatment, on the grounds that the former and not the latter falls outside the goals of medicine and therefore cannot qualify as "legitimate" therapy or "good" medical practice (McCormick in Chan 1993:219, Dondrop et al. 2010: 812).

Notions such as legitimate or good medical practice are notoriously open to interpretation. Nevertheless, efforts have been made to define what qualifies as good medical practice using an analysis of the goals of medicine. To take this route, one needs first to offer a plausible conception of the goals of medicine and offer an argument for whether all or only some of the possible goals should qualify, such as the prevention of disease and injury, the avoidance of premature death, pain relief and relief of suffering from maladies, or the promotion and maintenance of health or quality of life (see, e.g., Brülde 2001; Callahan 1999). 
However, for the point we wish to make, we need not define the goals of medicine. We acknowledge that the definition of the goals of medicine will matter for whether IVF treatments fall within or outside these goals - but not that this settles the issue of IVF with ROPA for lesbian couples. If one adheres to the view that the only goal of medicine is the alleviation of suffering from maladies and pain, IVF treatment for individuals with fertility problems may fall within the scope of medicine in contrast to such treatment for those who are involuntarily childless for non-medical reasons. If the analysis of goals of medicine instead results in health promotion being defined as a goal of medicine, IVF treatment for involuntary childlessness for medical and other reasons may fall within the scope of medicine. One may suggest, as Dondrup and colleagues (2010:813) do, that such treatment can contribute to individuals' reproductive health "in a broader sense,” though this hinges on what is seen as an acceptable definition of health.

Importantly, if IVF with ROPA for lesbians with fertility problems falls outside the goals of medicine (if, say, infertility is not seen as stemming from maladies), then this is also the case for many other examples of assisted reproduction. Likewise, if IVF with ROPA for lesbians without fertility problems falls outside the goals of medicine (because it implies involuntary childlessness for nonmedical reason), then the same is the case for heterosexual couples with idiopathic infertility where the female partner is close to the end of her reproductive life span - because this form of infertility is not due to a medical condition (cf. Dondrop et al. 2010). IVF with ROPA for lesbians who have spare frozen embryos and wish to implant them falls, in the same way, outside or inside the scope of medicine as does IVF with spare embryos for heterosexuals.

\section{The importance of biological bonds}

Let us now turn to the use of IVF with ROPA for women with no medical reasons to undergo the treatment (and with no spare embryos to utilize), i.e. where IVF with ROPA is asked for primarily to create a child with shared biological bonds to both mothers, or when one partner desires a genetic offspring but does not wish to become pregnant. On the one hand, in contexts where biological bonds and the sharing of such bonds are attributed value, and where heterosexual couples' wish to share 
biological bonds continues to be met, it seems reasonable to argue that the same wish should be met for lesbians. On the other hand, biomedical technologies are influenced by and formed in relation to cultural and political norms and values, as becomes particularly evident in the field of reproductive medicine where the dream of having a child interacts with self-understandings, with norms of motherhood and fatherhood, and with the value attributed to genes and gestation in parenthood (Fuscaldo and Savulescu 2005; Ravin et al. 1997; Mahowald and Stocking 1997; Franklin 1997; Alpern 1992). Some such norms and values need to be critically examined and questioned. Among them, we suggest, is the norm according to which women should want to experience pregnancy, as well as the value attributed to genetic bonds, at the expense of the value of the rearing relation between parent and child.

The emphasis on biological parenthood recur in studies where couples attribute value to shared genetic bonds and see such shared bonds as enabling the flourishing of parent-parent-child relations. Indeed, empirical studies show that some infertile heterosexual couples who undergo IVF with egg or sperm donation experience unequal genetic ties as resulting in emotional complexities, such as jealousy and resentment (Becker 2000; Ragoné 1994). Likewise, studies of lesbian mothers show that these mothers emphasize the importance of relational equality, and indicate that unequal genetic ties can cause emotional complexities in the relationships (Pelka 2009; Hayden 1995; Malmquist submitted). Whereas emotional complexities may have various causes, and whereas this research is still inconclusive, it nevertheless suggests that a partially shared genetic bond may be complex for some lesbian couples but not for others.

Having said this, we also caution against a narrow focus on biological bonds. At this point, it is useful to return to the differentiation between genetic parenthood, gestational parenthood, and intentional parenthood. These forms of parenthood can but need not be combined. Tim Bayne and Avery Kolers (2003) argue for a pluralist sufficiency account of parenthood, where one or more of the grounds for parenthood are sufficient but not necessary. Each of these grounds, instead, is sufficient for parenthood, and this sufficiency is derived from the causal role of intention or gestation or genes for the child's existence and survival. 
While acknowledging the many routes to and kinds of parenthood and in light of the focus on biological bonds in assisted reproduction generally, we underline the importance of attributing value to the rearing dimension of parenthood - and this on the basis of a conception of the parent-child relation in terms of mutuality, where the parent-child relation develops over time, and where the significance of this relation for the flourishing of child and parent is acknowledged (cf. Murray and Kaebnick 2003). ${ }^{4}$ To this we add a call, on the one hand, for a response of care for and sympathy with those who long for a biologically related child and who would like to undergo IVF in order make this possible and, on the other hand, for a critical examination of the value attributed to biological bonds and how this feeds into the development of assisted reproduction technologies. We need to focus not only on whether the use of IVF is ethically permissible but also on the social and political context in which assisted reproduction technologies are being developed, the reasons for this, and how the value attributed to biologically related children may be strengthened within this area at the expense of other parent-child relations.

\section{Contrasting IVF with ROPA to egg donor IVF and live uterus transplantation}

We have already contrasted IVF with ROPA for lesbians with intracytoplasmic sperm injection for heterosexuals where the male partner has low sperm production and IVF for women near the end of their reproductive period. In the following, we will more extensively contrast IVF with ROPA for lesbians with fertility problems to two forms of assisted reproduction technologies for heterosexual women with fertility problems, namely egg donor IVF and live uterus transplantation with IVF.

\footnotetext{
${ }^{4}$ Furthermore, assisted reproduction technologies both promote and undermine the idea that biological relationships have great significance for parent-child relations: Whereas IVF without a donor is a route to a child with genetic bonds to two parents, IVF with gamete donation for heterosexuals separates social from genetic parenthood, and IVF with ROPA allows for genetic motherhood without pregnancy and gestational motherhood without genetic bonds.
} 


\section{IVF with ROPA and egg donor IVF for heterosexuals}

Both IVF with ROPA and egg donor IVF for heterosexuals involve three individuals who will have a biological link to the child: in the first case a gestational mother, a genetic mother and a sperm donor, and in the second case a gestational mother, a genetic father and an egg donor. In both cases, the involved persons are the intended parents and a gamete donor. What can make an ethical difference between these cases?

Consider first the risks. The risks for the gestational mothers, related to pregnancy and delivery, are equal in the two cases. However, in egg donor IVF for heterosexual couples, the third part - the egg donor - will undergo the ovarian hormonal stimulation and egg retrieval. This person will thereby bear IVF-related risks in order to enable the bringing into existence of a child that she won't parent. This is the case when egg donors are recruited among healthy women who otherwise would not undergo IVF treatment (which is ordinary practice in Sweden). In other cases (such as in the UK), where egg donors may also be recruited among women undergoing IVF themselves (and where surplus eggs could be donated in order to reduce treatment fee), ${ }^{5}$ the egg donor would not undergo IVF-related risks solely for the purpose of donating eggs to others. This egg retrieval strategy, however, raise other potential ethical complexities if women involved in IVF treatment have difficulty saying no when asked if they would like to donate their surplus eggs to other women.

For the lesbian couple with fertility difficulties, in contrast, the third part is a sperm donor who does not bear any medical risks. All medical risks are in this case born by the ones who will parent the child. This can make IVF with ROPA for lesbian women with impaired fertility, from the perspective of IVF-related risks, less ethically problematic than egg donor IVF for heterosexual couples: in IVF with ROPA, the individuals who undergo IVF-related risks do so for the sake of having a child together.

\footnotetext{
${ }^{5}$ See http://www.eggsharing.com/. See also Haimes 2013.
} 
In other regards, IVF with ROPA and egg donor IVF evoke equal ethical concerns. The IVFrelated risks for the child seems not to be higher with ROPA. Since both IVF with ROPA for lesbians with impaired fertility and egg donor IVF for heterosexual couples are performed in order to overcome infertility, both will either fall outside or inside the goals of medicine.

\section{IVF with ROPA and live uterus transplantation IVF}

Consider also IVF with ROPA for women with impaired fertility in contrast to live uterus transplantation. Both of these routes to the longed-for child are performed in order to overcome female infertility. If this is seen as a decisive factor when it comes to whether a treatment qualifies as falling within the goals of medicine, then both routes to the child do so. Furthermore, in the light of the question of the value of shared biological bonds, live uterus transplantation would imply a fully shared genetic bond in cases where the woman has eggs of her own and her male partner is fertile. If she has no eggs but the partner is fertile, and if live uterus transplantation would be combined with egg donation, the male partner would be the genetic father and the female partner the gestational mother. Just as in the case of IVF with ROPA, the parents would have a shared biological bond to the child.

A difference becomes evident when one considers the level of risks involved in these two routes to parenthood. Though it is important to take account of IVF-related risks in relation to IVF with ROPA, IVF is an established procedure. This is not the case with live uterus transplantation in its present stage of development. Live uterus transplantations have been performed, but no embryo implantation has yet succeeded. Because of the newness of the method, it becomes crucial that everyone involved is aware of the risk uncertainty. Previous studies on pregnancy after maternal organ donation (particularly live kidney donation), i.e. pregnancy when the gestational mother is on immunosuppressants, indicates heightened risks for pregnancy complications such as risks for miscarriage, risks for preterm birth, low birth-weight and of smallness for gestational age for the child (Tendron et al. 2002, Dianne et al. 2006). Whereas these risks are seen as unrelated to the immunosuppressive treatment as such and instead due to the medical status of the woman (Källén et al. 2005), some scholars also state that the effects of immunosuppressants can be difficult to determine 
and may not be obvious at birth (Dianne et al. 2006). Furthermore, whereas other studies show that there is a small risk for graft rejection during pregnancy among women with transplanted kidneys (Armenti et al. 2002), graft rejection in the case of live uterus transplantation - i.e. rejection of the uterus - could have a major impact on the child. And to this we also need to add the IVF related risks already discussed.

Consider also the cultural value attributed to biological bonds, and in this case, to pregnancies. Previous studies have examined how young women who have no uterus and no or a so-called small vagina negotiate cultural norms about female embodiment, and sometimes question the assumption that womanhood implies a certain female body and certain experiences that are typically female (such as gestation) and sometimes declare that they really would like to undergo pregnancy - and to know what it feels like to be pregnant - and to share experiences that they describe as typically female (Guntram 2013, Zeiler and Guntram 2014).

In the light of such research, it is noteworthy that women who become pregnant after uterus transplantation may not feel the foetus's movements from "the inside", at least if the transplant procedure does not include connection of nerves to the transplanted uterus (Catsanos et al. 2013). A correct understanding of what the procedure implies is important in order to avoid later complex emotions of having undergone a tough procedure without what may be the expected result, i.e. to experience pregnancy just like other women, apart from the longed-for child.

\section{The case of Sweden: Returning to Martina and Agnes}

Swedish legislation forbids IVF with ROPA. This is a consequence of a paragraph that prohibits embryo donation (SFS 2006:351). We will now trace this prohibition back to the first Swedish legislation on IVF and to discussions in the Swedish National Council of Medical Ethics on the value of a genetic bond between the child and at least one of its parents.

The first Swedish law regulating IVF treatment, in 1988, restricted the treatment to involving only heterosexual couples and homologous IVF, i.e. no donors (SFS 1988:711). Seven years later, the National Council of Medical Ethics (1995) published a report where they called for legislative 
changes. The Council argued that because donor semen was already allowed in inseminations (SFS 1984:1140), donor semen should also be allowed in IVF treatments. Furthermore, they argued, egg donor IVF should also be allowed because male and female infertility should be valued equally. At this time, the Council emphasized the value of a genetic bond between the child and at least one of the parents. It was stated that the acceptance of no genetic link between parents and child would imply a far-reaching endeavor to compensate for the imperfection of life using technical means, and risked causing gametes to be perceived as objects freely disposable for the creation of a human being. The Council dissuaded combined egg and sperm donation.

Eight years later, in 2003, legislature followed the recommendations of the Swedish National Council of Medical Ethics. IVF treatment with either donor semen or donor eggs was allowed for heterosexual couples, while embryo donation was forbidden. The new regulation on IVF treatment in the third paragraph of Law on fertilization outside the body (SFS 1988:711) reads:

A fertilized egg may be transferred into a woman's body only if the woman is married or cohabitant and the husband or cohabitant has given his written consent for this. If the egg is not the woman's own, it shall have been fertilized with the husband's or cohabitant's sperm [our translation]. ${ }^{6}$

The next revision of the law of relevance for our present reasoning took place in 2005, and opened the door to donor insemination and donor IVF for lesbian couples. This revision was preceded by an extensive governmental proposal as regards how to adjust the law to female partners in assisted reproduction treatment (Ds 2004:19). The original reading of IVF regulations was kept intact with the

\footnotetext{
${ }^{6}$ The original text in Swedish reads: ”Ett befruktat ägg får föras in i en kvinnas kropp endast om kvinnan är gift eller sambo och maken eller sambon skriftligen samtyckt till detta. Om ägget inte är kvinnans eget skall ägget ha befruktats av makens eller sambons spermier.”
} 
amendment that what the law says about spouses also applies to lesbian couples. For lesbian couples, this gave access to fertility treatment in public health care and enabled shared juridical parenthood.

However, applying the same regulations for same-sex and different-sex couples may sometimes not give equal opportunities. As outlined above, the law stated that a fertilized egg implanted into a woman's body shall be one of her own egg unless fertilized with her partner's sperm. For a heterosexual woman, the law allows her to become pregnant with a child genetically related to her partner and a gamete donor, but prohibits embryo donation. For a lesbian woman, the same paragraph means that she can neither carry a child conceived through embryo donation, nor a child that is genetically linked to her partner and a gamete donor. Because of this formulation, ROPA became legally impossible, regardless of the couple's motives for desiring this treatment, and even though the child in fact would have a genetic bond to one of its parents, which was deemed ethically crucial.

The prohibition of IVF with ROPA may be a consequence of a heteronormative point of departure, in the sense that the formulation takes as its point of departure the heterosexual couple's situation. Legislature did not consider IVF with ROPA when revising the law. The legislation also underwent an additional comprehensive revision in 2006, and yet the section of relevance for ROPA remained intact (SFS 2006:351).

However, the Swedish National Council on Medical Ethics (2013) has recently changed its view on embryo donation and published a report on assisted reproduction where it recommends legislature to permit embryo donation - a genetic bond to one parent is no longer deemed ethically crucial. This report presents pros and cons for this position, and emphasizes that a genetic bond can be less important for the child's well-being than other factors including social bonds between parents and children. The report discusses ROPA as a form of embryo donation (labelled donation of fertilized eggs), gives examples of medical and social reasons for lesbians to desire ROPA, but focuses heavily on infertile heterosexual couples' reasons for desiring embryo donation. It argues that because IVF treatments often leave surplus embryos, utilizing only these embryos would cover infertile couple's needs. Hence, only donation of surplus embryos from couples in IVF treatment to other couples should be legalized. 
Again, this reasoning omits that lesbian couples are not identical to heterosexual couples when it comes to assisted reproduction. Lesbian couples could desire IVF treatment with another couple's donated surplus embryos, but the suggestion in the report would not allow them to use IVF with ROPA. If legislature again follows the recommendations from the Swedish National Council on Medical Ethics, IVF with ROPA would continue to be forbidden, but with no ethical arguments presented for the prohibition. For Martina and Agnes, this means that they could not turn to Swedish health care to have a third child: Agnes will not undergo yet another high-risk pregnancy and Martina will not undergo insemination or IVF treatment with her own eggs for age-related reasons.

Consider, one final time, IVF with ROPA in relation to egg donor IVF for heterosexual couples and live uterus transplantation. As seen above, egg donor IVF has been allowed in Sweden since 2003. Live uterus transplantation is not specifically mentioned in Swedish law, neither in relation to regulations on transplantations (SFS 1995:831), nor in relation to other regulations on assisted reproduction (SFS 2006:351). However, the Law on patient security (SFS 2010:659) states that health care must be performed based on science and proven experience. Because live uterus transplantation is not (yet) an established treatment, it is not (yet) allowed within regular Swedish health care. A permission to perform the treatment within a research project has been given, and the treatment is practiced within that context. IVF with ROPA is the only of these three assisted reproduction treatments that is prohibited by law. In light of our reasoning above, however, IVF with ROPA seems to be less ethically problematic than both some cases of egg donor IVF and live uterus transplantation with IVF.

\section{Conclusion}

The article offers an analysis of ethical arguments for and against IVF with ROPA and contrasts it to other forms of assisted reproduction, in particular egg donor IVF and live uterus transplantation with IVF. We conclude that IVF with ROPA for lesbians with impaired fertility gives rise to fewer ethical questions than does live uterus transplantation, and in some cases also egg donor IVF. 
Our point is not to criticize the current Swedish practice of egg donor IVF or of live uterus transplantation (even if both of these, including other forms of assisted reproduction technology need to be continuously examined), but to highlight the inconsistency of ethical reasoning in the present Swedish situation. Swedish legislation prohibits ROPA but allows the other two practices. The reasonableness of this outcome is ethically weak and could perhaps best be understood as reflecting a heteronormative bias in the legislation on assisted reproduction, in the sense that the law takes the heterosexual couple’s situation as its point of departure.

\section{Acknowledgements}

The article is part of Malmquist's work within the project Swedish Lesbigay Families in the 21st Century - Parenthood in a Time of Legislative Changes, financed by the Swedish Research Council for Health, Working-life, and Welfare, and of Zeiler's work as Pro Futura Scientia Fellow. The Pro Futura Scientia Program is a collaboration between the Swedish Collegium for Advanced Study, Uppsala University and Riksbankens Jubileumsfond. We thank all these for financial support for this research.

\section{References}

Alpern, K. 1992. Genetic puzzles and stork stories: On the meaning and significance of having children. In K. Alpern (ed) The ethics of reproductive technology (147-169). New York. Oxford University Press.

Armenti, V.T. et al. Immunosuppression in Pregnancy: Choices for Infant and maternal Health. Drugs 2002: 62; 2361-2375.

Baker, M. The elusive pregnancy. Choice and empowerment in medically assisted conception. Women's Health and Urban Life 2004: III (1); 34-55.

Bayne, T. and A. Kolers. Toward a pluralist account of parenthood. Bioethics 2003: 17(3); 221-242. 
Becker, G. 2000. The elusive embryo: How women and men approach the new reproductive technologies. Berkeley: University of California Press. For a related discussion in the area of surrogacy.

Biblarz, T. and J. Stacey. How does the gender of parents matter? Journal of Marriage and Family 2010: 72(1); 3-22.

Boorse, C. Health as a theoretical concept. Philosophy of Science 1977: 11(1); 542-573.

Bos, H. and F Van Balen. Children of new reproductive technologies: social and genetic parenthood. Patient Education and Counseling 2010: 81(3); 429-235.

Brülde, B. The goals of medicine. Towards a unified theory. Health care analysis. 2001: 9; 1-13.

Callahan, D. Remembering the goals of medicine. Journal of Evaluation in Clinical Practice 1999: 5(2); 103-106.

Catsanos, R., Rogers, W. and M. Lotz. The ethics of uterus transplantation. Bioethics 2013: 27(2); 6573.

Chan, C.S. Fox, J.H. and R.A. McCormick. The Forum: Lesbian motherhood and genetic choices. Ethics \& Behaviour 1993: 3(2); 219.

Clarke V. Feminist perspectives on lesbian parenting: A review of the literature 1972-2002. Psychology of Women Section Review 2005: 7(2); 11-23.

Delvigne, A. and S. Rozenberg. Epidemology and prevention of ovarian hyperstimulation syndrome (OHSS): a review. Human Reproduction Update 2002: 8(6); 559-577.

Dianne, B., McKay, M.D., and M. A. Josephson. Pregnancy in Recipients of Solid Organs - Effects on Mother and Child. The New England Journal of Medicine 2006: 354(12); 1281-1293.

Dondrop, W.J., De Wert, G.M., and P.M.W. Janssens. Shared lesbian motherhood: a challenge of established concepts and frameworks. Human reproduction 2010: 25(4); 812.

Ds 2004:19 Föräldraskap vid assisterad befruktning för homosexuella [Governmental report: Parenthood in assisted reproduction for homosexuals].

European Society of Human Reproduction and Embryology. Comparative Analysis of Medically Assisted Reproduction in the EU: Regulation and Technologies. Report, 2009. 
Fageeh, W., Raffa, H., Jabbad, H. and A. Marzouki. Case report: Transplantation of the human uterus. Int J Gynecol Obstet 2002; 76: 245-251.

Franklin, S 1997. Embodied progress: A cultural account of assisted conception. London: Routledge.

Fuscaldo, G. and J. Savulescu. Spare embryos: 3000 reasons to rethink the significance of genetic relatedness. Reproductive BioMedicine Online 2005: 10(2), 164-168.

Gross, M. 'Objective Culture' and the Development of Nonknowledge: Georg Simmel and the Reverse Side of Knowing. Cultural Sociology 2012: 6(4); 422-437.

Guntram, L. "Differently normal" and "Normally different": Negotiations of sexed embodiment in women's accounts of 'atypical' sex development. Social Science \& Medicine 2013: (98): 232238.

Hansen, A. Swedish surgeons report world's first uterus transplantations from mother to daughter. BMJ 2012: 345; 6357.

Haimes, E. Juggling on a rollercoaster? Gains, loss and uncertainties in IVF patients' accounts of volunteering for a U.K. ‘egg sharing for research’ scheme. Social Science \& Medicine 86:45-51.

Hayden, C.P. Gender, genetics and generation: Reformulating biology in lesbian kinship. Cultural Anthropology 1995: 10; 41-63.

Källén, B., Westgren, M. and A. Åberg, P. Otterblad Olausson. Pregnancy outcome after maternal organ transplantation in Sweden. BJOG: An International Journal of Obstetrics and Gynaecology 2005: 112; 904-909.

Kirkman, M. and D. Rosenthal. Representations of Reproductive technology in Women's Narratives of Infertility. Women \& Health 1999: 29(2): 17-36.,

Lundin, S. 1997. Guldägget: Föräldraskap i biomedicinens tid. Lund, Sweden: Historiska media.

Malmquist, A. Women in lesbian relations: Construing equal or unequal parental roles. Submitted 2013.

Malmquist, A., Möllerstand, A., Wikström, M. and Zetterqvist Nelson, K.'A daddy is the same as a mummy': Swedish children in lesbian households talk about fathers and donors. Childhood 2013: pre-published on-line. DOI: 10.1177/0907568213484342 
Malmquist, A. and Zetterqvist Nelson, K. Efforts to maintain a 'just great' story: Lesbain parents' talk about encounters with professionals in fertility clinics, and maternal and child healthcare services. Feminism \& Psychology 2013: pre-published on-line. DOI: $10.1177 / 0959353513487532$

Marina, S., Maria, D., Marina, F., Fosas, N., Galiana, F., and I, Jové. Sharing motherhood: biological lesbian co-mothers, a new IVF indication. Human reproduction 2010: 25(4); 930-941.

Murray, T.H. and G.E. Kaebnick. Genetic ties and genetic mixups. Journal of Medical Ethics 2003: 29; 68-69.

Nordenfelt, L. 2000. Action, ability and Health. Essays in the Philosophy of Action and Welfare. Dordrecht, Boston, London: Kluwer Academic Publishers.

Pelka, S. Sharing motherhood: Maternal jealousy among lesbian co-mothers. Journal of homosexuality 2009: 56(2); 195.

Ragoné, H. 1994. Surrogate motherhood: Conceptions in the heart. Oxford: Westview Press.

Ravin, A.J., Mahowald, M.B. and C.B. Stocking. Genes or Gestation? Attitudes of Women and Men about Biological Ties to Children. Journal of Women’s Health 1997: 6; 639-647.

Redshaw, M., Hockley, C. and L.L. Davidson. A qualitative study of the experience of treatment for infertility among women who successfully became pregnant. Human Reproduction 2007: 22(1); 295-304.

Rozental, A. and Malmquist, A. Vulnerability and acceptance: Lesbian women's family-making through assisted reproduction in Swedish public healthcare. Journal of GLBT Family studies. Accepted 2013.

SFS 1984:1140. Lag on insemination [Law on Insemination].

SFS 1988:711. Lag om befruktning utanför kroppen [Law on fertilization outside the body].

SFS 1995:831. Lag om transplantation m.m. [Law on transplantation etc.]

SFS 2006:351. Lag om genetisk integritet m.m. [Law on Genetic Integrity etc.].

SFS 2010:659. Lag om patientsäkerhet [Law on patient security] 
Simon, L., Brunborg, G., Stevenson, M., Lutton, D., McManus, J., and S.E.M. Lewis. Clinical significance of sperm DNA damage in assisted reproduction outcome. Human Reproduction 2010: 25(7); 1594-1608.

Slovik, P and E.U. Weber. 2002. Perception of Risk Posed by Extreme Events. In Risk management strategies in an uncertain world. Columbia/Wharton Roundtable, Palisades, NY. Retrieved from

http://www.ldeo.columbia.edu/chrr/documents/meetings/roundtable/white_papers/slovic_wp.pd f.

Söderström-Anttila, V. Pregnancy and child outcome after oocyte donation. Human Reproduction. 2001 Jan-Feb: 7(1); 28-32.

Steuber, K.R. and D. H. Solomon. Relational uncertainty, partner interference, and infertility: A qualitative study of discourse within online forums. Journal of Social and Personal Relationships 2008: 25; 831-855.

Tendron, A., Gouyon, J-B., and S. Decramer. 2002. In utero exposure to immunosuppressive drugs: experimental and clinical studies. Pediatric Nephrology 17(1): 121-130.

The Swedish National Council of Medical Ethics. Assisterad befruktning - synpunker på vissa frågor $i$ samband med befruktning utanför kroppen. [Assisted reproduction - aspects on some questions in relation to fertilization outside the body.] Report. Stockholm. 1995.

The Swedish National Council on Medical Ethics. Assisterad befruktning - etiska aspekter. [Assisted reproduction - ethical aspects.] Report. Stockholm. 2013:1.

Verhaak, C.M, Smeenk, J.M.J., .Evers, A.W.M, Kremer, J.A.M., Kraaimaat, F.W., and D.D.M.Braat. Women's emotional adjustment to IVF: a systematic review of 25 years of research. Human Reproduction Update 2007: 13(1); 27-36.

World Health Organization, Constitution of. 1948. Official Records of the World Health Organization.

Zeiler, K and L. Guntram. Sexed Embodiment in Atypical Pubertal Development: Intersubjectivity, Excorporation and the Importance of Making Space for Difference. In Feminist Phenomenology 
and Medicine, edited by K Zeiler and L Folkmarson Käll. New York: State University New York Press, 2014 (In Press). 